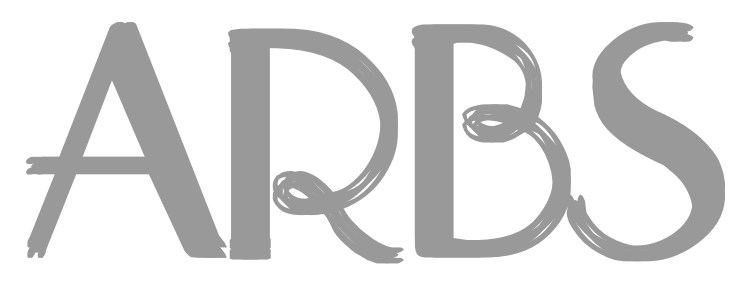

A BARTKE ${ }^{1}$, V CHANDRASHEKAR ${ }^{2}$

${ }^{1}$ Departments of Physiology and Medicine ${ }^{2}$ Department of Physiology Southern Illinois University School of Medicine, USA

\title{
Reproductive Function in Long Lived Mice: Effects of Mutations and Caloric Restriction
}

\section{Contents}

Abstract

Introduction

Hypopituitary Dwarf Mice

GH Deficient Little Mice

GH resistant Laron Dwarf Mice

Partially IGF-1 Resistant Heterozygous IGF-1 Receptor KO Mice

Other Long-lived Gene Knock-out Mice

Discussion

References

\section{Abstract}

In laboratory stocks of mice and rats, caloric restriction (CR) prolongs life but inhibits reproduction. It is believed that in response to food shortage, the animals can activate a "survival program" that favors stress resistance and repair processes at the expense of growth, reproductive development, and fertility. In two hypopituitary mouse mutants, Ames dwarf (Prop $\mathrm{l}^{\mathrm{df}}$ ) and Snell dwarf (Pit $\mathrm{l}^{\mathrm{dw}}$ ), life span is prolonged by as much as $65 \%$, postnatal growth and adult body size are severely reduced, and puberty is greatly delayed. Fertility of male dwarf mice is reduced and females are sterile due to prolactin (PRL) deficiency and the consequent luteal failure. In "Laron dwarf mice" with targeted disruption of growth hormone $(\mathrm{GH})$ receptor gene, $\mathrm{GH}$ resistance leads to dramatic depression of peripheral levels of insulin-like growth factor 1 (IGF-1), reduction of adult body size by approximately 50\%, a slight but significant delay of female and male puberty,

\section{Correspondence}

Andrzej Bartke

Geriatrics Research, Departments of Physiology and Medicine, Southern Illinois University School of Medicine, P.O. Box 19628, Springfield, Illinois 62794-9628, USA.

E-mail: abartke@siumed.edu

Finantial support: NIH, NICHD, NIA and Illinois C-Far. 
and extension of life span by $30-50 \%$. Both genders are fertile but various measures of reproductive competence including time to conception and litter size in females and testosterone responses to $\mathrm{LH}$ in males are reduced. Plasma PRL levels are elevated while FSH levels are reduced. Holzenberger and his colleagues (2003) recently reported that female mice heterozygous for IGF-1 receptor knock-out live approximately 30\% longer than normal mice, have nearly normal adult body weight, and are fully fertile. Males have similar phenotype but the apparent increase in longevity was not statistically significant. These results, as well as recent findings in worms and insects indicate that the well documented reciprocal relationship between reproductive effort and longevity does not apply to all animals with increased life expectancy. Reduced GH and IGF-1 signaling is compatible with fertility and a modest level of IGF-1 resistance can prolong life without a negative impact on reproduction. We are currently examining the interactive effects of $\mathrm{CR}$ and mouse longevity genes on reproductive functions.

Key words: reproduction, dwarf mice, growth hormone receptor knock-outs.

Invited Mini-review

\section{Introduction}

There are many examples of reciprocal relationship between reproduction and longevity. Most long lived species of mammals have late puberty, long gestations, small litter size, and large intervals between litters often combined with a long period of parental care. Large ungulates and primates provide many examples of this type of life history, with humans clearly fitting this pattern. In contrast, animals which mature early, have short gestation periods, and produce large and frequent litters are generally short lived. Most small rodents fit in this category. Comparison of mice derived from wild populations with mice from standard laboratory stocks and strains indicates that domestication in this species was associated with advancement of puberty, increase in litter size and reduction of life expectancy (Miller et al., 2000).

In laboratory populations of mice and rats, aging can be delayed and lifespan extended by reducing the amount of food the animals are allowed to consume, the socalled dietary or caloric restriction (CR) (reviewed in Weindruch \& Walford, 1988; Masoro, 2001; Hursting et al., 2003). CR is the only intervention that consistently produces significant increase of longevity in mammals. It was also shown to be effective in domestic dogs (Kealy et al., 2002) with evidence of similar responses in beef cattle (Pinney et al., 1972) and in monkeys (Lane et al., 2001), and there are reasons to believe that it could be applied to delay human aging. In rodents subjected to CR, puberty is delayed, and fertility is suppressed (Weindruch \& Walford, 1988; Masoro, 2001; Hursting et al., 2003). Female mice subjected to CR typically do not cycle and thus presumably are sterile while female 
rats have reduced litter size (Weindruch \& Walford, 1988; Masoro, 2001; Hursting et al., 2003; Holehan \& Merry, 1985). In the latter species, the effect of reduced litter size on life time fertility may be partially offset by a delay in reproductive aging and thus longer period of reproductive competence (Holehan \& Merry, 1985). Separating the beneficial effect of CR on longevity from its detrimental effect on reproduction may be difficult. It is believed that CR affects aging by activating a genetic program which shifts the animals from a growth and reproduction mode to the survival/stress resistance mode, thus allowing the animal to respond to scarcity of food by postponing reproduction until environmental conditions improve.

Recent interest in the genetic control of aging resulted in identification of many mutations that prolong life in organisms ranging from yeast to mammals (reviewed in Guarente \& Kenyon, 2000; Jazwinski, 2001; Tissenbaum \& Ruvkun, 1998; Tatar et al., 2003). Although exceptions exist, many of the long lived mutants in Caenorhabditis elegans, Drosophila melanogaster and mice have reduced fertility and in many cases one of the sexes is sterile. In C. elegans many of the known longevity genes promote entry into the so-called dauer, a larval stage that does not feed or reproduce. This presumably represents an adaptation to lack of food and increased population density, and provides an important mechanism for survival and dispersal.

There is great interest in utilizing the knowledge gained from the studies of $\mathrm{CR}$ and longevity genes to design anti-aging interventions that could be applied to the human. These could include dietary regiments acceptable to the general population, CR mimetics and pharmaceutical interventions based on the mechanism(s) of action of longevity genes. The generally reciprocal relationship between longevity and reproductive competence is of obvious concern in this regard. Compromising sexual and reproductive functions would represent unacceptable change in the quality of life, and reduced levels of gonadal steroids could lead to serious health problems including reduction in bone mineral density and increasing the risk of osteoporosis and fractures.

In this context, we will summarize available information on reproductive function in long lived mutant mice. Both natural mutations and targeted disruption of specific genes (the so-called knock-out, KO) will be discussed.

\section{Hypopituitary Dwarf Mice}

Mice homozygous for recessive loss-of-function mutations at the prophet of pituitary factor 1 (Prop $1^{\mathrm{df}}$ ) or pituitary factor 1 (Pit $1^{\mathrm{dw}}$ ) locus live 35\% to 65\% longer than normal animals from the same stock (Brown-Borg et al., 1996; Flurkey et al., 2001). Both Ames dwarf (Prop $1^{\mathrm{df}}$ ) and Snell dwarf (Pit $1^{\mathrm{dw}}$ ) mice have primary deficiency of growth hormone $(\mathrm{GH})$, prolactin (PRL), and thyroid-stimulating hormone (TSH) because the corresponding cell types in the anterior pituitary fail to differentiate during fetal development (Li et al., 1990; Sornson et al., 1996). Consequently, postnatal growth and adult body size are greatly reduced, the animals are hypothyroid and exhibit a characteristic 
dwarf phenotype (Bartke, 1979 ; Bartke, 1979 ; Bartke, 2000a). Sexual maturation is delayed and gonadal function reduced with the extent of these impairments depending strongly on genetic background. Snell dwarf mice from the inbred Dwarf/J strain are severely hypogonadal with females failing to undergo puberty and males exhibiting significant reductions in the number of advanced germ cells in the testes and in the weight of accessory reproductive glands (Bartke \& Lloyd, 1970). In contrast, in stocks maintained on heterogeneous genetic background, females undergo apparently normal, although delayed sexual development with establishment of estrous cycles and period of sexual receptivity, and males have complete and quantitatively nearly normal spermatogenesis, are fertile, and can be used as breeders (Bartke, 1979ª Bartke, 1979 ${ }^{\mathrm{b}}$; Bartke, 2000a Bartke \& Lloyd, 1970). Plasma gonadotropin levels are reduced, presumably as a secondary consequence of GH, PRL, and TSH deficiency. Replacement therapy with GH, PRL or thyroxine can increase the levels of luteinizing hormone (LH) and/or follicle stimulating hormone (FSH) (Bartke et al., 1977; Doherty et al., 1980; Chandrashekar \& Bartke, 1993). In Ames dwarf mice, treatment with bovine GH increased LH responses to exogenous LH releasing hormone (LHRH), partially normalized LH responses to gonadectomy and to testosterone replacement, and increased testosterone and androstenedione responses to human chorionic gonadotropin in vitro (Chandrashekar \& Bartke, 1993).

Female dwarf mice with spontaneous or hormonally-induced sexual maturation can produce fertilizable ova and mate, but do not become pregnant because they lack PRL which, in a mouse, is absolutely required for establishment of normal luteal function and support of pregnancy. Providing PRL replacement by means of injections or transplants of normal pituitaries under the kidney capsule allows both Snell and Ames dwarf mice to become pregnant, produce live pups and raise them to weaning (Bartke, 1965; Bartke, 1973). During pregnancy, exogenous PRL administration is required only during the first 8 days after mating (Bartke, 1973), because afterwards mouse corpus luteum depends on placental lactogen rather than pituitary PRL, and production of placental lactogen in dwarf mice is normal or perhaps slightly increased (Soares et al., 1984).

\section{GH Deficient Little Mice}

$\mathrm{GH}$ releasing hormone receptor deficient little $\left(G H R H R^{\text {lit }}\right)$ mice have isolated GH deficiency and are smaller than normal (Eicher \& Beamer, 1976). Life span of little mice on C57 BL/ 6 background is prolonged by approximately $25 \%$ if their obesity is prevented by maintaining them on a low fat diet (Flurkey et al., 2001). Little mice are fertile, but male reproductive functions are quantitatively reduced (Chubb, 1987).

\section{GH Resistant Laron Dwarf Mice}

Targeted disruption of GH receptor/GH binding protein gene was used to produce mice with $\mathrm{GH}$ resistance due to deficiency of $\mathrm{GH}$ receptor, a syndrome analogous to Laron dwarfism in the human (Zhou et al., 1997). Animals homozygous for the disrupted 
gene (GHR-KO -/-) produce increased levels of GH, presumably due to absence of negative feedback, but fail to respond to GH and have dramatically reduced levels of insulin-like growth factor 1 (IGF-1) in peripheral circulation leading to reduced post weaning growth and diminutive adult body size (Zhou et al., 1997). Lifespan of GHR-KO animals is increased by 46\% (Coschigano et al., 2000). Both females and males are fertile but their gonadal function and fertility are reduced in comparison to normal $(+/+$ and $+/-)$ animals of the same strain. Females exhibit delayed puberty which can be advanced by a brief period of treatment with IGF-1 (Danilovich et al., 1999). Adult GHR-KO females have reduced number of ovarian follicles and corpora lutea and reduced litter size (Zhou et al., 1997; Bachelot et al., 2002; Zaczek et al., 2002). These deficits may be combined with early reproductive aging, although this conclusion is controversial (Bachelot et al., 2002). In the ovaries of estrous GHR-KO mice produced in our colony, expression of IGF-1 was reduced but expression of key steroidogenic enzymes was not affected (Zaczek et al., 2002). Bachelot et al. (2002), reported no attenuation in ovarian expression of IGF-1 or any of the examined IGF-1 binding proteins in GHR-KO mice.

In GHR-KO - / - (compared to +/+ and -/+) males, puberty is delayed (Keene et al., 2002), LH responses to LHRH as well as testicular responses to LH are reduced (Chandrashekar et al., 1999) with the latter deficit likely being due to reduced number of LH receptors in the testis (Chandrashekar et al., 2001). Moreover, the number of PRL receptors in the testis is reduced and the ratio of testosterone to androstenedione is diminished (Chandrashekar et al., 2001), possibly reflecting reduced PRL signaling in spite of elevated PRL levels in the circulation (Chandrashekar et al., 1999). Although most of GHR-KO males are fertile, several measures of fertility are reduced in comparison to normal (+/+ and +/-) animals (Chandrashekar et al., 1999).

\section{Partially IGF-1 Resistant Heterozygous IGF-1 Receptor KO Mice}

In contrast to severe developmental deficits and early mortality of mice homozygous for disruption of the IGF-1 receptor, the animals heterozygous for this condition are only slightly smaller than normal and live significantly longer (Holzenberger et al., 2003). Average life span was increased by $33 \%$ in females and appeared to be longer also in males (Holzenberger et al., 2003). Both females and males are fertile and several indices of female reproductive function and reproductive aging were indistinguishable from normal $(+/+)$ controls (Holzenberger et al., 2003).

\section{Other Long-lived Gene Knock-out Mice}

Modest, but statistically significant extension of life span and normal fertility were reported in mice with targeted gene disruption of the $\mathrm{p} 66^{\text {shc }}$ gene which is involved in stress responses (Migliaccio et al., 1999), and in mice with adipose tissue-specific disruption of the insulin receptor and the resulting decrease in body fat content (Bluher et 
al., 2003). We are not aware of any information on the age of sexual maturation, reproductive hormone levels, or quantitative measures of reproductive performance in these animals.

\section{Discussion}

Earlier in this chapter, we have listed seven spontaneous or experimentally produced mutations which extend life span in laboratory stocks of house mice (Mus musculus). Five of these seven mutations reduce function of the somatotropic axis by causing GH deficiency, GH resistance or partial IGF-1 resistance. Existence of reproductive deficits in four of these five mutants is consistent with the well documented roles of GH and IGF-1 in the control of sexual maturation (Ramaley \& Phares, 1980; Hiney et al., 1996) and adult reproductive function (reviewed in Adashi, 1998; Bartke, 2000; Hull \& Harvey, 2000 ; Hull \& Harvey, 2002). These findings are also consistent with the generally reciprocal relationship between longevity and functions regulated by the somatotropic axis including growth, maturation, and adult body size. However, the intriguing recent findings in IGF-1 receptor $\mathrm{KO}(+/-)$ mice suggest that a modest reduction in somatotropic signaling can prolong life and be compatible with normal reproductive development and function (Holzenberger et al., 2003). Apparent disassociations of the effects on life span from the effects on reproduction was achieved also by knockout of genes that increase resistance to oxidative stress or produce insulin resistance of adipocytes (Migliaccio et al., 1999; Bluher et al., 2003). Detailed information on reproductive development and function of $\mathrm{p} 66^{\text {shc }}$ and fat insulin receptor $\mathrm{KO}$ (FIRKO) mice would be of considerable interest.

Interpretation of finding in GHR-KO mice is complicated by the possibility that effects of $\mathrm{GH}$ resistance caused by targeted disruption of the GHR gene may be partially offset by compensatory adjustments. Significant elevation of circulating prolactin (PRL) levels in male and in ovariectomized female GHR-KO mice (Chandrashekar et al., 1999) represents such potential adjustment. Some of the biological actions of PRL overlap those of $\mathrm{GH}$ and it is conceivable that the preserved, although quantitatively reduced reproductive competence of GHR-KO animals is related to enhanced PRL secretion. Physiological compensatory adjustments can reduce and, in some cases, completely mask the phenotypic consequences of gene knockout. However, in GHR-KO mice, this appears unlikely, because most of their phenotypic characteristics correspond to the expected effects of $\mathrm{GH}$ resistance.

It is unclear whether reduced gonadal activity in GHR-KO, or other long lived mutant mice contributes in any way to extension of life span. Ablation of germ cells extends longevity in C. elegans (Hsin \& Kenyon, 1999) and sterility can increase life span in Drosophila (Sgro \& Partridge, 1999). Gonadectomy is reported to increase life span in males (Drori \& Folman, 1976). Negative association of reproductive functions and longevity in mammals is more likely due to alterations in growth, metabolic rate, regulation of carbohydrate metabolism, and energy partitioning than to differences in gonadal status. 
Ames and Snell dwarf mice are hypothyroid (Bartke, 1979; Li et al., 1990; Sornson et al., 1996; Bartke, 2000ª and levels of thyroid hormones are reduced also in GHR-KO mice (Hauck et al., 2001). Alterations in function of the somatotropic axis together with the associated hypothyroidism and hypoinsulinemia are likely to influence energy metabolism, partitioning of food-derived energy, and generation of reactive oxygen species. Hypoglycemia likely reduces non-enzymatic glycation of proteins and generation of advanced glycation end products (AGE).

It should be emphasized that IGF-1 signaling, insulin signaling, and oxidative stress are believed to represent major evolutionary conserved mechanisms of aging. Therefore reproductive consequences of genetic manipulation of these pathways are likely to be relevant to most of the interventions that could slow aging and prolong life. Study of mutants with alterations in pituitary functions or GH signaling provide interesting opportunity to further clarify the roles of GH and IGF-1 in the control of female and male reproductive functions, to separate the roles of $\mathrm{GH}$ dependent vs. GH independent biosynthesis of IGF-1 and to gather new information in the intricate relationships between growth, reproduction, and aging.

\section{References}

Adashi EY. The IGF family and folliculogenesis. J Reprod Immunol 1998;39:13-9.

Bachelot AMP, Imbert-Bollare P, Coschigano K, Kopchick JJ, Kelly PA, Binart N. Growth hormone is required for ovarian follicular growth. Endocrinology 2002;143:4104-12.

Bartke A. Influence of luteotrophin on fertility of dwarf mice. J Reprod Fertil 1965;10: 93-103.

Bartke A, Lloyd CW. The influence of pituitary homografts on the weight of the accessory reproductive organs in castrated male mice and rats and on mating behavior in male mice. J Endocrinol 1970;46:313-20.

Bartke A. Differential requirement for prolactin during pregnancy in the mouse. Biol Reprod 1973;9:379-83.

Bartke A., Goldman BD, Bex F, Dalterio S. Effects of prolactin (PRL) on pituitary and testicular function in mice with hereditary PRL deficiency. Endocrinology 1977; 101:1760-6.

Bartke A. Genetic models in the study of anterior pituitary hormones. In: Shire JGM. Genetic Variation in Hormone Systems. Boca Raton, CRC Press;1979ª :113-26.

Bartke, A. Prolactin-deficient mice. In: Alexander NJ. Animal Models for Research on Contraception and Fertility. Hagerstown, Harper \& Row; $1979^{\mathrm{b}}: 360-5$.

Bartke A. Delayed aging in Ames dwarf mice. Relationships to endocrine function and body size. In: The Molecular Genetics of Aging. Hekimi. Berlin Heidelberg, Springer-Verlag; $2000^{\mathrm{a}}: 29: 181-202$.

Bartke A. Effects of growth hormone on male reproductive functions. J Androl $2000^{\mathrm{b}} ; 21: 181-8$.

Bluher M, Kahn BB, Kahn CR. Extended longevity in mice lacking the insulin receptor in adipose tissue. Science 2003;299:572.

Brown-Borg HM, Borg, KE Meliska CJ, Bartke A. Dwarf mice and the ageing process. Nature 1996;384:33. 
Chandrashekar V, Bartke A. Induction of endogenous insulin-like growth factor-1 secretion alters the hypothalamic-pituitary-testicular function in growth hormone-deficient adult dwarf mice. Biol Reprod 1993;48:544-51.

Chandrashekar V, Bartke A, Coschigano KT, Kopchick JJ. Pituitary and testicular function in growth hormone receptor gene knockout mice Endocrinology 1999;140:1082-8.

Chandrashekar V, Bartke A, Awoniyi CA et al. Testicular endocrine function in growth hormone receptor gene disrupted mice. Endocrinology 2001;142:3443-50.

Chubb C. Sexual behavior and fertility of little mice. Biol Reprod 1987;37:564-9.

Coschigano KT, Clemmons D, Bellushll, Kopchickk JJ. Assessment of growth parameters and life span of GHR/BP gene-disrupted mice. Endocrinology 2000;141:2608-13.

Danilovich N, Wernsing D, Coschigano KT et al. Deficits in female reproductive function in GH-R-KO mice; role of IGF-I. Endocrinology 1999;140:2637-40.

Doherty PC, Bartke A, Dalterio S et al. Effects of growth hormone and thyroxine on pituitary and testicular function in two types of hereditary dwarf mice. J Exp Zool 1980;214:53-9.

Drori D, Folman Y. Environmental effects on longevity in the male rat: exercise, mating, castration and restricted feeding. Exp Gerontol 1976;11:25-32.

Eicher EM, Beamer WG. Inherited ateliotic dwarfism in mice. Characteristics of mutation, little, on chromosome 6. J Hered 1976;67:87-91.

Flurkey K, Papaconstantinou J, Miller RA, Harrison DE. Lifespan extension and delayed immune and collagen aging in mutant mice with defects in growth hormone production. Proc Natl Acad Sci USA 2001;98:6736-41.

Guarente L, Kenyon C. Genetic pathways that regulate ageing in model organisms. Nature 2000;408:255-62.

Hauck SJ, Hunter WS, Danilovich N et al. Reduced levels of thyroid hormones, insulin, and glucose, and lower body core temperature in the growth hormone receptor/binding protein knockout mouse. Exp Biol Med 2001;226:552-8.

Hiney JK, Srivastava V, Nyberg CL et al. Insulin-like growth factor I of peripheral origin acts centrally to accelerate the initiation of female puberty. Endocrinology 1996;137:3717-28.

Holehan AM, Merry BJ. The control of puberty in dietary restricted female rat. Mech Ageing Dev 1985;32:179-91.

Holzenberger M, Dupont J, Ducos B et al. IGF-1 receptor regulates lifespan and resistance to oxidative stress in mice. Nature 2003;421:182-7.

Hsin H, Kenyon C. Signals from the reproductive system regulate the lifespan of C. elegans. Nature 1999;399:308-9.

Hull KL, Harvey S. Growth hormone: A reproductive endocrine-paracrine regulator? RevReprod 2000;5:175-82.

Hull KL, Harvey S. GH as a co-gonadotropin: the relevance of correlative changes in GH secretion and reproductive state. J Endocrinol 2002;172:1-19.

Hursting SD, Lavigne JA, Berrigan D, Perkins SN, Barrett JC. Calorie restriction, aging, 
and cancer prevention: mechanisms of action and applicability to humans. Annu Rev Med 2003;54:131-52.

Jazwinski SM. New Clues to Old Yeast. Mech Ageing Dev 2001;122:865-82.

Kealy RD, Lawler DE, Ballam JM et al. Effects of diet restriction on life span and agerelated changes in dogs. J Am Vet Med Assoc 2002;220:1315-20.

Keene DE, Suescun MO, Bostwick MG et al. Puberty in male growth hormone receptor gene disrupted mice. J Androl 2002;23:661-8.

Lane MA, Black A, Handy A et al. Caloric restrictions in primates. Ann NY Acad Sci 2001;928:287-95.

Li S, Crenshaw EB $3^{\text {rd }}$, Rawson EJ et al. Dwarf locus mutants lacking three pituitary cell types result from mutations in the POU-domain gene pit-1. Nature 1990;347:528-33.

Masoro EJ. Dietary Restriction: An Experimental Approach to the Study of the Biology of Aging. In: Masoro EJ, Austad SN. Handbook of The Biology of Aging (5th Edition). San Diego: Academic Press; 2001:396-420.

Migliaccio E, Giorgio M, Mele S et al. The p66she adaptor protein controls oxidative stress response and life span in mammals. Nature 1999;402:309-13.

Miller RA, Dysko R, Chrisp C. Mouse (Mus Musculus) stocks derived from tropical islands: New models for genetic analysis of life history traits. J Zool 2000;250: 95-104.

Pinney DO, Stephens DF, Pope LS. Lifetime effects of winter supplemental feed level and age at first parturition on range beef cows. J Anim Sci 1972;34:1067 -74.

Ramaley JA, Phares CK. Delay of puberty onset in females due to suppression of growth hormone. Endocrinology 1980;106:1989-93.

Sgro CM, Partridge L. A delayed wave of death from reproduction in Drosophila. Science 1999;286:2521-24.

Soares MJ, Bartke A, Colosi P, Talamantes F. Identification of a placental lactogen in pregnant Snell and Ames dwarf mice. Proc Soc Exp Biol Med 1984;175:06-8.

Sornson MW, Wu W, Dasen JS et al. Pituitary lineage determination by the prophet of pit1 homeodomain factor defective in Ames dwarfism. Nature 1996;384:327-33.

Tatar M, Bartke A, Antebi A et al. The endocrine regulation of aging by insulin-like signals. Science 2003;299:1346-51.

Tissenbaum HA, Ruvkun G. An insulin-like signaling pathway affect both longevity and reproduction in Caenorbabditis elegans. Genetics 1998;148: 703-17.

Weindruch R, Walford R. The Retardation of Aging and Disease by Dietary Restriction. Springfield, Illinois, Charles C.Thomas,1988.

Zaczek D, Hammond J, Suen L et al. Impact of growth hormone resistance on female reproductive function: New insight from growth hormone receptor knockout mice. Biol Reprod 2002;67:1115-24.

Zhou Y, Xu BC, Maheshwari HG et al. A mammalian model for Laron syndrome produced by targeted disruption of the mouse growth hormone receptor/binding protein gene (The Laron mouse). Proc Natl Acad Sci USA 1997;94:13215-20. 
